\title{
Post traumatic knee stiffness managed by modified Judet's quadricepsplasty - what we achieved by surgery
}

\author{
Ramprasath R Dhurvas, ${ }^{1, *}$, Karthikeyan $\mathbf{K}^{2}$ \\ ${ }^{\mathbf{1}}$ Associate Professor, ${ }^{2}$ Junior Resident, Dept. of Orthopaedics, Institute of Orthopaedics and Traumatology, Coimbatore Medical \\ College Hospital, Coimbatore, Tamil Nadu, India \\ *Corresponding Author: Ramprasath R Dhurvas \\ Email: dhurvasramprasath@gmail.com
}

\begin{abstract}
Introduction: Post traumatic stiffness of knee joint developing after injury with or without surgical intervention is a difficult condition to manage. Surgical management of knee stiffness includes Thompson's quadricepsplasty and Judet's quadricepsplasty. Materials and Methods: We have performed modified Judet's quadricepsplasty in two cases of post traumatic knee stiffness. One patient with $0-10^{\circ}$ movements achieved post operative range of gain of flexion of $80^{\circ}$. Another case with $0-20^{\circ}$ movements achieved post operative range of gain of flexion of $70^{\circ}$. Judet's criteria was used to analyse the movements. We achieved "good" results in both the cases.

Conclusion: Thompson's quadricepsplasty has problems like extension lag and wound dehiscence. Modified Judet's quadricepsplasty with step wise release seems to be the preferred procedure with lesser complication rates and better outcome. Functional outcome depends on post operative pain relief, physiotherapy and patient's cooperation.
\end{abstract}

Keywords: Thompson's quadricepsplasty, Judet's quadricepsplasty, Post traumatic knee stiffness, Step wise release, Knee contracture.

\section{Introduction}

Post traumatic knee stiffness can be caused by flexion contracture, extension contracture or combined contracture (affecting both flexion and extension). ${ }^{1}$ The stiffness has two components intraarticular and extra articular. ${ }^{1}$ Though extension contracture of knee are less common than the flexion ontracture they are more prone to cause deformity especially in Asian countries where kneeling down is a part of daily routine. ${ }^{2}$ Quadricepsplasty is done to achieve flexion in extension contractures. Thompson's quadricepsplasty (distal quadricepsplasty) was previously used, but because of significant extension $\operatorname{lag}^{3}$ this procedure is not much used nowadays. In 1956, Judet proposed an alternative technique involving proximally based quadriceps muscle slide with stepwise release of knee and quadriceps. ${ }^{3,4} \mathrm{We}$ are presenting two cases of post traumatic knee stiffness treated with modified Judet's quadricepsplasty.

\section{Materials and Methods}

We have operated on two patients with the extension contracture of knee using modified Judet's quadricepsplasty. The results were analysed using Judet's criteria. ${ }^{2,3}$ Modified Judet's quadricepsplasty (according to Dror Paley) consists of 5 steps

Step-1: (Intra articular release): Only the distal part of the incision was made to release the knee adhesions from the lateral side (Fig. 1).

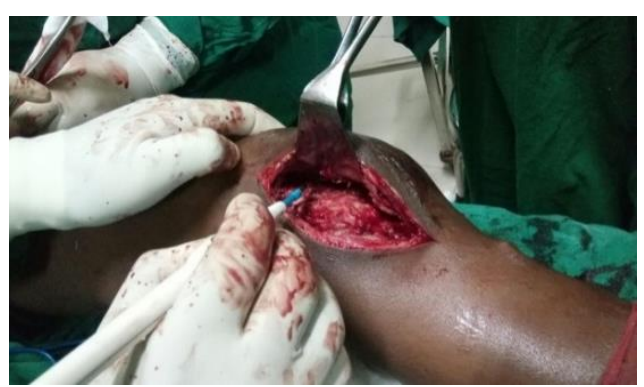

Fig. 1: Intra articular release lateral side

Step-2: (MCL and Medial capsular release): Medial capsule was cut through a short medial incision, arthrolysis was performed. MCL was elevated off the tibia distally (Fig. 2).

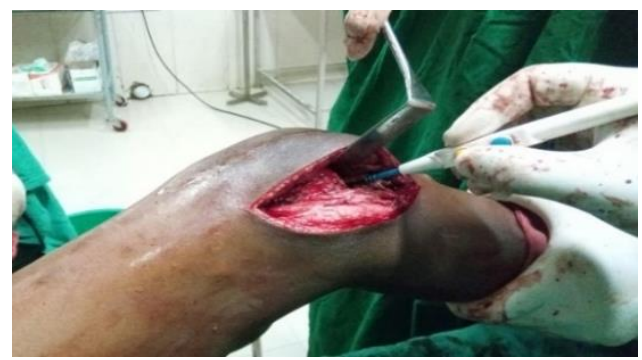

Fig. 2: MCL and medial capsular release

Step-3: (Rectus femoris release): A small bikini line inguinal incision of approximately 3 to $4 \mathrm{~cm}$ was made and the rectus identified and transected (Fig. 3). 


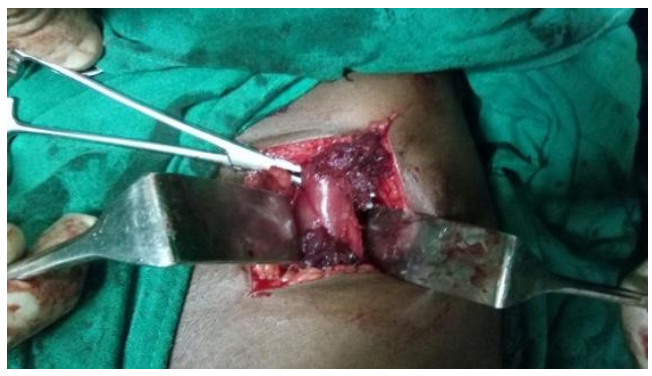

Fig. 3: Rectus femoris release

Step-4: (Quadriceps muscle slide): The lateral incision was extended proximally to the greater trochanter. The vastus lateralis was divided from the linea aspera with meticulous attention to hemostasis of the large perforating vessels. The vastus intermedius was then identified and lifted extraperiosteally off the lateral and anterior surfaces of the femur. If fibrosis was present, the fibrotic parts of the vastus intermedius were resected (Fig. 4).

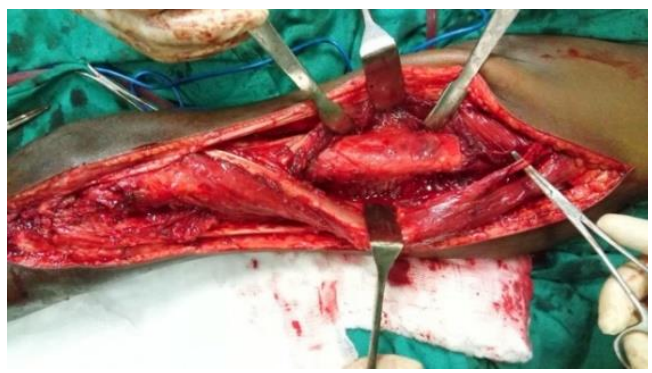

Fig. 4: Quadriceps muscle slide

Step-5: Fractional lengthening of Fascia lata and anterior Fascia of Thigh (Fig. 5). Multiple stab incisions were made in the fascia lata and anterior fascia of thigh.

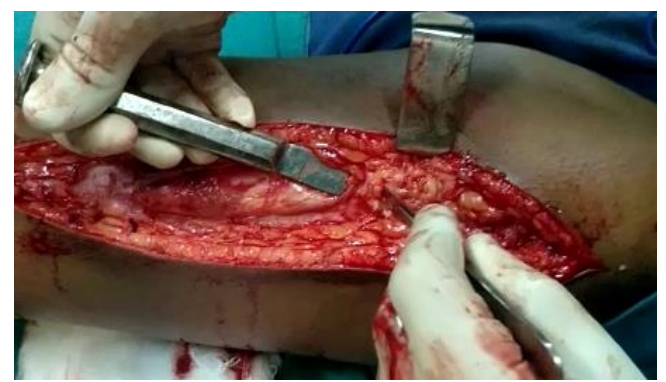

Fig. 5: Fractional lengthening of fascia lata and anterior fascia of thigh

Case 1: A 36 year old male patient with history of Road Traffic Accident sustained a Grade IIIA fracture both bone right leg proximal third and shaft of femur fracture on the ipsilateral side. The both bone leg fracture was treated with wound debridement and skeletal stabilisation with external fixator and the patient was put on calcaneal pin traction. After 20 days of injury, the shaft of femur fracture was treated by open reduction and internal fixation with intramedullary nailing. After 30 days of injury, the external fixator (tibia) was removed after the wound had healed and the patient was put on above knee plaster cast. The cast was removed after three months and mobilisation was started. The patient developed infection at the shaft of femur fracture site and implant exit was done after 18 months (once the fracture was united). The patient was on physiotherapy for knee mobilisation for 6 months and one manipulation under anaesthesia was tried. Still the patient had only $10^{\circ}$ of flexion $\left(0^{\circ}\right.$ to $10^{\circ}$ range of motion). The patient underwent modified Judet's quadricepsplasty after 2 years of injury. Intra operative flexion of about $90^{\circ}$ was achieved (Fig. 6) and the final flexion at follow up was $90^{\circ}$ with no extension lag and the gain of flexion was $80^{\circ}$. According to Judet's criteria, the result was "good".

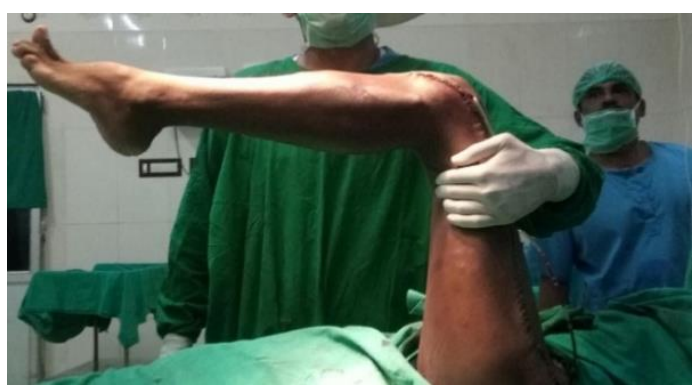

Fig. 6: Range of flexion achieved by surgery in case 1

Case 2: A 19 year old male patient with history of Road Traffic accident had sustained fracture of the distal femoral condyle for which open reduction and internal fixation with screws was done one year back. Postoperatively the patient had been immobilised with above knee slab for two months. Then the slab was removed and mobilisation was started. But at presentation the knee was fixed in $20^{\circ}$ of flexion (with no further flexion / extension). The patient underwent modified Judet's quadricepsplasty after one year of injury. Flexion of $100^{\circ}$ was achieved intra operatively (Fig. 7) and the final flexion post operatively was $90^{\circ}$ (Fig. 8). There was gain of flexion of $70^{\circ}$. According to Judet's criteria, the result was "good".

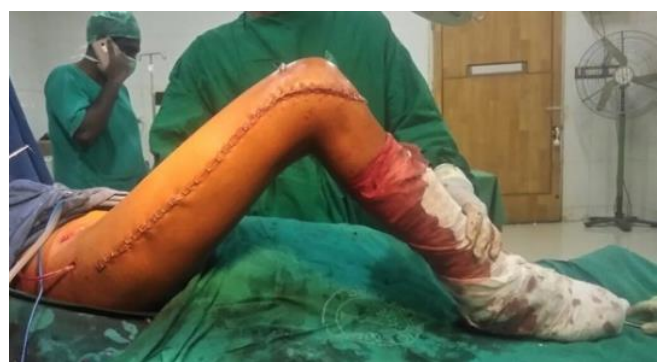

Fig. 7: Range of flexion achieved by surgery in case 2 


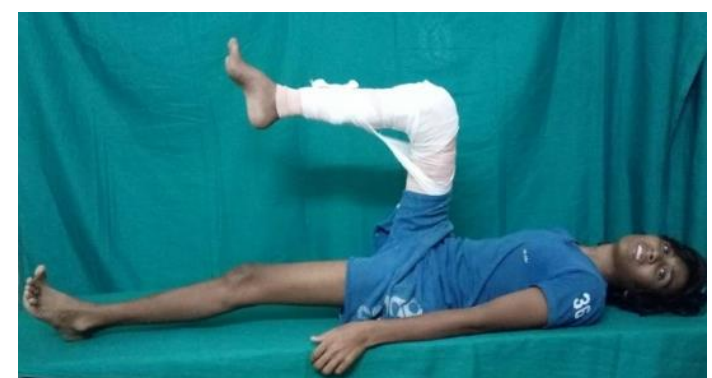

Fig. 8: Post operative clinical picture showing range of flexion

\section{Discussion}

In patients with post traumatic stiffness having extension contracture, the source of pathology may be 1) Intra articular adhesions, 2) Adhesions of the quadriceps, Quadriceps bursae, patellar retinaculum, 3) Posterior impingement (femoral malunion), 4) Patellar baja. ${ }^{1}$ Thompson's quadricepsplasty involves detachment of vastus medialis, lateralis and intermedius from the patella so that rectus femoris is the sole extensor of the knee. $^{5-7}$ Therefore a significant extension lag was observed. ${ }^{4}$ A modified Thompson's approach was later developed, ${ }^{5,8}$ in which two small parapatellar incisions and a lateral or antero lateral incision on the distal thigh were made to reduce problems with wound healing. Moreover the insertion of the vastus medialis at the patella was preserved. This procedure is claimed to reduce the extension lag. Dror Paley introduced modified Judet's quadricepsplasty. The advantages of modified Judet's quadricepsplasty includes 1) Sequential release is done so that the procedure can be stopped when adequate flexion is achieved 2) Lateral incision provides good wound healing 3) Extra periosteal release of vastus intermedius prevents recurrence of adhesions to bone 4) The extension lag is minimal because the vasti are not detached from their insertion to patella.

Masse et $\mathrm{al}^{9}$ showed a mean flexion gain (Judet's technique) of $72.1^{\circ}$. Ebraheim et al showed a mean flexion gain of $53^{0} .{ }^{10}$ Akbar Jaleel et al showed a mean flexion gain of $47.6^{0}$. In our study we achieved a flexion gain of $70^{\circ}$ in one patient and $80^{\circ}$ in another patient.

Before performing quadricepsplasty any fractures must be healed, thus a 3- 6 months waiting period is required. Surgery must be delayed if active CRPS is suspected. Moreover the results of mobilisation procedures are not as good beyond six months. ${ }^{1}$

There is practically no role for isolated manipulation under anesthesia. This may lead to iatrogenic fracture in distal femur / proximal tibia. We encountered one such case where manipulation was done under anesthesia resulting in a fracture of distal femur. Open reduction and plating was done under same anesthesia.

The maximum range of motion possible using the limb's weight recorded at the end of the procedure will be the final range of motion even after physiotherapy. To maintain this range of motion the following principles should be adopted 1) Limit the risk of post operative hematoma (this decreases the risk of scar tissue) by keeping the surgical drain for at least 2 days. 2) Start intermittent mobilisation once the patient arrives in recovery room. 3) Adequate pain relief during, before, and after the physiotherapy sessions will provide good cooperation from the patient. ${ }^{1}$

\section{Conclusion}

Post traumatic stiffness of the knee joint can be avoided by early physiotherapy post operatively. Once stiffness is established, a modified Judet's quadricepsplasty provides adequate range of motion with less chances of extensor lag. Post operative pain management and early mobilisation are the key to successful outcome.

\section{References}

1. N. Pujol, P. Boisrenoult, P. Beaufils Post-traumatic knee stiffness: Surgical techniques.

2. Service d'orthopédie, université Versailles-Saint Quentin, centre hospitalier de Versailles, 177, rue de Versailles, 78157 Le Chesnay, France dx.doi.org/10.1016/j.otsr.2014.06.026

3. Akbar Jaleel Zubairi, Haroon Rashid, Rizwan Haroon Rashid, Moiz Ali, Pervaiz Mehmood Hashmia. Outcome of Judet's quadricepsplasty for knee contractures and the effect of local infiltration of epinephrine on reducing blood loss. PMID: 28554591

4. Bari MM, Islam S, Shetu NH, Rahman W, Rahman M. Judet's Quadricepsplasty for Extension Contracture of the Knee (Stiff Knee). MOJ Orthop Rheumatol. 2015;2(6):00071. DOI: 10.15406/mojor.2015.02.00071

5. Bellemans J, Steenwerckx A, Brabants K, et al: The Judet quadricepsplasty: A retrospective analysis of 16 cases. Acta Orthop Belg. 1996;62:79-82.

6. S. B. Hahn, W. S. Lee, D. Y. Han. A modified Thompson quadricepsplasty for the stiff knee. J Bone Joint Surg. 2000;82-B:992-5.

7. Hesketh KT. Experience with the Thompson's quadricepsplasty. J Bone Joint Surg Br. 1963;45-B:491-5.

8. Thompson TC. Quadricepsplasty to improve knee function. J Bone Joint Surg Br. 1944;26:366-79.

9. Hahn SB1, Choi YR, Kang HJ, Lee SH. Prognostic factors and long-term outcomes following a modified Thompson's quadricepsplasty for severely stiff knees. $J$ Bone Joint Surg Br. 2010;92(2):217-21. doi: 10.1302/0301-620X.92B2.22936

10. Masse A, Biasibetti A, Demongos J. The Judet quadricepsplasty: long -term outcome of 21 cases. $J$ Trauma. 2006;61:358-362. http: //dx.doi.org/10.1097/01.ta.0000230281.31144.1d.

11. Ebraheim NA, De Troye RJ, Saddemi SR. Results of Judet quadricepsplasty. J Orthop Trauma. 1993;7:327330.http://dx.doi.org/10.1097/00005131-19930800000007.

How to cite this article: Ramprasath D.R, Karthikeyan K. Post traumatic knee stiffness managed by modified Judet's quadricepsplasty - what we achieved by surgery. Indian J Orthop Surg. 2018;4(4):402-404. 